\title{
Spratlies Archipelago as the Australasian Tektite Impact Crater, Details of Formation \& Richard Muller's Dust Cloud Explanation for the Mid-Pleistocene Ice Age Cycle Transition
}

\author{
Hermann G. W. Burchard \\ Department of Mathematics, Oklahoma State University, Stillwater, USA \\ Email: skeptiker@icloud.com
}

How to cite this paper: Burchard, H.G.W. (2018) Spratlies Archipelago as the Australasian Tektite Impact Crater, Details of Formation \& Richard Muller's Dust Cloud Explanation for the Mid-Pleistocene Ice Age Cycle Transition. Open Journal of Geology, 8, 1-8.

https://doi.org/10.4236/ojg.2018.81001

Received: December 6, 2017

Accepted: January 12, 2018

Published: January 15, 2018

Copyright $\odot 2018$ by author and Scientific Research Publishing Inc. This work is licensed under the Creative Commons Attribution International License (CC BY 4.0).

http://creativecommons.org/licenses/by/4.0/

\begin{abstract}
Several significant events of a geological nature occurred approximately 800 ka before the present: (1) Australasian tektite fall (AA), (2) Brunhes-Matuyama geomagnetic reversal (BMR), (3) mid-Pleistocene changes in ice age cycles. Add to these the undated fault system (4) in the South-West (SW) of the South China Sea (SCS). Here we offer a unified cause for all four of these in (5), an impact in the SCS of a large, massive cosmic object, likely a comet, obliquely coming from the SW at an extremely shallow angle, striking the Sunda shelf yet unexploded with the shock of its compressed air bow wave, and causing the continual shelf and slope to collapse, resulting in the fault system (4), then traveling almost tangentially to the surface, exploding at impact with the sea surface, ejecting the tektites (1), creating the formation underlying the later atolls of Spratlies Archipelago (6), Nansha Islands in Chinese, \& causing the BMR (2). An explanation of event (3) was Richard Muller's hypothesis of planet Earth passing through an interplanetary dust cloud periodically due to ecliptic precession. Here we hypothesize this cloud actually is a belt of Australasian tektites ejected into space at super-orbital velocities that Earth encounters about every $100 \mathrm{ka}$.
\end{abstract}

\section{Keywords}

Spratlies Archipelago, Cosmic Object Impact Crater, Australasian Tektites, Brunhes-Matuyama Geomagnetic Reversal, Richard Muller Dust Cloud Hypothesis, Mid-Pleistocene Ice Age Cycle Transition,

Google Earth High Resolution Update 


\section{Introduction: Australasian Tektite Impact Crater Apparent from Google Earth High Resolution Update}

For quite a long time, the best explanation known for the changes in the ice age cycles at about $800 \mathrm{ka}$ has been the Interplanetary Dust Cloud hypothesis of Richard Muller [1], [2]. We can now hypothesize this cloud actually is a belt of Australasian tektites (AA) ejected into space at super-orbital velocities that Earth encounters about every $100 \mathrm{ka}$ due to ecliptic precession, according to Muller's theory. The timing, moreover, seemed to coincide with events related to the Brunhes-Matuyama geomagnetic reversal, which in turn appeared to be caused by the Australasian tektite fall [3], that now can be identified with a cosmic object impact, likely a comet, striking the South China Sea (SCS), giving rise to the formation underlying the later atolls of the Spratlies Archipelago, known as Nansha Islands in Chinese. Petroleum geologists \& engineers began exploring the South China Sea several decades ago \& discovered that the Australasian impact crater was located just off the Vietnamese coast, but only rumors came to be known, with no scientific publication forthcoming, perhaps due to concerns in the oil industry of a proprietary nature. This rumored scenario now can be confirmed, and is available for viewing by the general public due to a recent high resolution update of Google Earth satellite map imagery, that clearly shows the crater centrally located in the South China Sea and identical in geographic extent with the Spratlies Archipelago.

This was first noted by me on or just prior to Nov. 3, 2013, when I looked at the satellite imagery with the idea that the rumored SCS location might be indicated in the maps. I immediately sent an email to the owner of a website devoted to related matters. This email amounted to a first draft of the current paper, and a more complete 2 nd draft was prepared in the following weeks, fully integrated with the literature available at the time, but was never submitted for publication $^{1}$. The present essay is essentially a reworked version of that 2 nd draft, with only minor revisions and a few additions, including one particularly significant recent study by Weiwei Ding \& Jiabiao Li, Oceanography Institute Hangzhou (2016).

The images are so precise and so clear that it is even possible to give a detailed narrative of events, the equivalent of someone providing a slideshow of the sequence of events. Moreover, this scenario serves to explain the odd and unusual features of this fall of tektites, their peculiar properties and shapes, including the large Muong Nong tektites. Apparently, the massive impactor's compressed air bow wave first struck the Sunda shelf, coming in from the South-West (SW) at an extremely shallow angle, \& cut a large embayment out of the North-East (NE) facing rim of the shelf.

Then, proceeding on its course \& dragging a pair of "snow-plow" tracks along, the large impacting body began to explode at the SW margin of the Spratlies in an explosion cone visible by its angular signature and then left concentric ellip-

${ }^{1}$ The recipient had posted my email online (his initiative): https://cosmictusk.com/crater-burchard/ 
tical contours where the explosion was fully consummated, centered at the site that now forms the basis of the Spratlies atolls.

Dates for tektite fall and magnetic reversal primarily given by Chinese geoscientists and archaeologists speak for the impact occurring $803 \mathrm{ka}$ and the reversal with a delay perhaps $786 \mathrm{ka}$ [4] [5] [6]. These dates agree better with the onset of longer cycles than the $1 \mathrm{Ma}$ epoch stated by Prof. Muller [2] [3]. Various fault systems and grabens are known in the region \& consistent with this interpretation-although the faults are routinely misdated [7]. A secondary objective of this paper is to refute an alternative explanation for the changes in the ice age cycles that has appeared very recently, an article in PNAS by Chalk et al. (Nov. 2017), entitled "Causes of ice age intensification across the Mid-Pleistocene Transition" [8], is purporting to explain the change in ice age cycles as caused by $\mathrm{CO}_{2}$ level variation.

This explanation would seem to be in contradiction to all available evidence that only $\mathrm{H}_{2} \mathrm{O}$ in its various forms as aerosol can cause substantial atmospheric heat retention, and that $\mathrm{CO}_{2}$ is not the driving green house gas, being completely irrelevant due to its minute contribution to our air. The latter fact was brought to this author's attention more than ten years ago, in a public statement by a Japanese meteorology and climate expert (whose identity though unavailable at present might be retrieved by searching past editions of a well-known online climate newsletter). These facts were demonstrated again earlier this year during the solar eclipse by the chill in the umbra region, as e.g. in my own backyard where the electronic thermometer showed the temperature dropping from $92^{\circ} \mathrm{F}$ to $86^{\circ} \mathrm{F}$ within minutes even though I had only $87 \%$ coverage being 250 miles from the 70 mile strip of totality. My air was calm and dry, under a cloudless sky. The tiny amount of $\mathrm{CO}_{2}$ in the air could not prevent radiative cooling. The same effect is routinely observed in calm nights when there is zero $\mathrm{H}_{2} \mathrm{O}$ vapor in the air. Also again, the date of $1 \mathrm{Ma}$ reported for the ice age cycle upheaval in the PNAS article [8] is too early.

\section{Spratlies Archipelago Astrobleme Cosmic Object Impact Structure}

This paper is based on multiple sources of indirect evidence, even including rumors that have persisted for decades, as well as my correcting mistakes in the evaluation of available data by prior researchers, but primarily hinges on geometry of an image: It rests on the detailed geometric analysis of satellite photographs published by Google Earth, who in turn are depending on others, several photographers \& documents.

As an applied mathematician, I have been involved regularly in the geometric analysis of images of great variety. This particular branch of evidentiary information is not always fully appreciated except by specialists, mathematicians, who are trained in this art \& science, but it is in fact a very powerful tool of science. Also essential, a lifetime of study of cosmic source impact phenomena as a subsidiary interest that has resulted in two prior publications [9], [10]. 
But foremost in my mind, always of paramount importance was the available ample data in the literature on the AA tektites, their configuration, composition and distribution, gathered by generations of numerous dedicated experts, see below, where I am able to cite only a small sampling of extant published works.

The recent update of Google Earth (GE), covering the ocean between Vietnam and the Philippines, the South China Sea is improved dramatically from earlier versions showing the Australasian tektite impact crater candidate in the Spratlies Archipelago, Nansha Islands in Chinese, and contested by a half dozen nations bordering the S China Sea, as well as the US, who claim this is international territory. One reason may be that the islands potentially are oil-rich.

Elliptical ovals underlying the Spratlies Archipelago are apparent in the recent Google Earth high resolution update of the South China Sea, Figure 1, concentric with a common center at map coordinates $9.82 \mathrm{~N}, 114.40 \mathrm{E}$.

Apparent as well is the track of the impactor, a presumptive comet, coming in almost tangentially from the SW, disrupting the Sunda shelf, heading NE, cutting a large embayment at $6.10 \mathrm{~N}, 110.02 \mathrm{E}$ and leaving behind a lateral pair of "snow plow" tracks. Details of the explosion cone are visible, that envelops the ovals, and is indicated by an angular contour with its vertex at $7.30 \mathrm{~N}, 112.5 \mathrm{E}$ with onset halfway toward the SW margin of the archipelago.

A multi-ring circular to oval impact structure is now clearly evident on the latest Google Earth updates. The diameter is about 175 miles $/ 275 \mathrm{~km}$, i.e., gigantic as expected from the large tektite strewn field, centered at 9.82 N, 114.40 E, clearly visible on recent updates of Google Earth. Presumably the crater will be dated eventually to approximately $800 \mathrm{ka}$.

The age is known fairly precisely for the strewn field at $803 \mathrm{ka}$, though not for the crater-this may be known to the oil men in the Spratlies. The fairly close

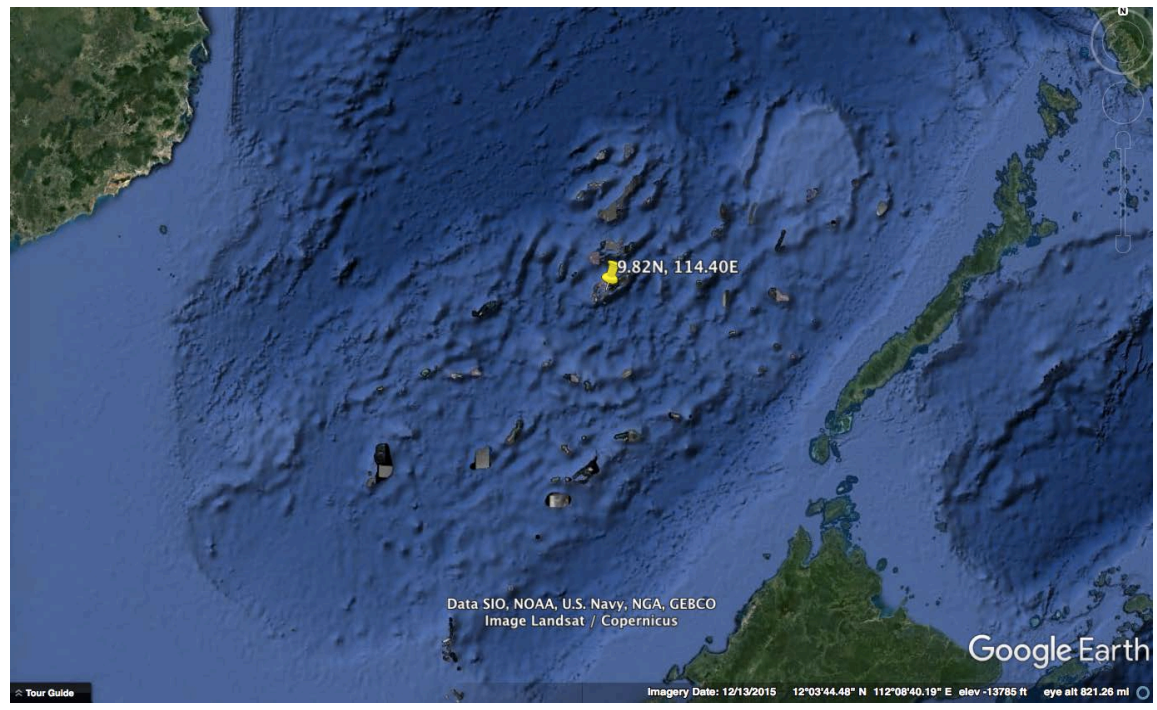

Figure 1. High resolution satellite map imagery of South China Sea showing details of impactor track from the Sunda shelf to the Spratlies Archipelago with the underlying concentric elliptical contours left by the impact explosion. Google Earth. 
agreement with the Brunhes-Matuyama geomagnetic reversal with a delay of about $16.5 \mathrm{ka}$ [11] was proven more than 10 years ago using Chinese loess sequences [4] [5].

\section{Refinement of Muller 100 ka Glacial Cycle Theory}

The $803 \mathrm{ka}$ Australasian tektite impact, long known to be nearly simultaneous with the Brunhes-Matuyama reversal at $786 \mathrm{ka}$ [3], did have a serious global effect, namely a major climate downturn making the ice-ages much more severe [6]. This is all the more remarkable, as we had known already that the Pleistocene's official starting date of $2.588 \mathrm{Ma}$ coincides with the Eltanin impact in the Southern Ocean which is also timed almost exactly to the Matuyama-Gauss reversal $^{2}$.

However, it appears that continental ice sheets did not come into the Mississippi valley before $786 \mathrm{ka}$, and that there were only six glacial cycles of $100 \mathrm{ka}$ periodicity [6]. And indeed the Younger Dryas Comet impact had a climate downturn and a major extinction event in its wake, as proven by Richard Firestone's splendid research, cf. comments in my Younger Dryas Comet paper [9], although no known geomagnetic effect occured. Therefore, it is here suggested that there is no obstacle for the Spratlies impact structure, with its unusual large size of $275 \mathrm{~km}$, to be seen as the AA tektite crater, with its causal relationship to the changes in the ice age cycle.

In this way, it becomes apparent that a refinement is available for the Richard Muller theory of the $100 \mathrm{ka}$ glacial cycle, explaining the recent $100 \mathrm{ka}$ cycle that overrides the Milankovic cycle of 40 ka periodicity [2] [3], by Earth's orbital plane precessing through his cosmic dust cloud once every $100 \mathrm{ka}$, putting Earth into an ice age each time the ecliptic passes through the dust cloud. In his original theory, Richard Muller ${ }^{3}$, proposed that a dust cloud arose at $1 \mathrm{Ma}$ from an asteroid main belt collision. But now it appears, from a large variety of source publications, that the $1 \mathrm{Ma}$ date is inaccurate and the $100 \mathrm{ka}$ cycle started with the AA tektite impact at $803 \mathrm{ka}$, Marine Isotope Stage (MIS) 20a [11], [12]. This adjustment seems indicated indisputably by evidence from MIS stages and glaciation cycles [6].

The best revised date for the BMR appears to be about $786 \mathrm{ka}$, MIS 19c.

By slightly adjusting his theory of precession of the ecliptic, the $100 \mathrm{ka}$ cycle started with the AA tektite impact at $803 \mathrm{ka}$, a date reported by Yamei \& al [4], not $1 \mathrm{Ma}$, and the Richard Muller cosmic dust cloud was not caused by an asteroid belt collision but rather, this is a cloud of AA tektites thrown into space and into orbit around the Sun by the exact same AA tektite impact that left the Spratlies Archipelago impact structure.

${ }^{2}$ For details, consult Wikipedia articles: https://en.wikipedia.org/wiki/Eltanin_impact, https://en.wikipedia.org/wiki/Gauss-Matuyama_reversal

${ }^{3}$ Professor of physics, UC Berkeley/Lawrence Berkeley National Laboratory, web-site: http://muller.lbl.gov/ 


\section{Sunda Land Shelf Origin of Australasian Tektites}

Why are there more tektites South rather than North if the Spratlies impactor went SW to NE [12]? The dirt thrown up into space was soil from the continental shelf and slope as both collapsed. The shelf is SW of the crater, the presumptive center of the main explosion, seconds after the shelf collapsed and its material dragged along, so clearly indicated by the pair of "snow-plow" tracks on either side of its SW to NE trajectory, so that material dominates the strewnfield plainly ejected toward the SW side.

The mysterious rifting in the SW China Sea has long been a puzzle to geologists but can now be understood on the basis of the Spratlies Archipelago impact structure, with a recent work dated 2016 providing fresh insight but still missing the Spratlies/Sunda shelf impact structure [13], [14]. Horsts and cuestas SW of the actual crater derive from the continental shelf and slope collapsing due to the impact explosion. Besides this one, there may well have been other impacts in the Sea and the wider region, as craters are a dime a dozen on all solid surface bodies in our solar system. The Miocene date stated by some authors for the rifting event is mere guess work. The paper entitled "What are the Spratly Islands?" by Hutchison and Vijayan reports about cores drilled in regions which were part of the slide when the impact caused the continental slope to collapse and slip toward the NE by several hundred $\mathrm{km}$, but does not deal with the impact crater itself [15].

\section{Compatibility of Spratlies Impact Structure with Known Characteristics of AA Tektites and Their Distribution}

According to the revised dates now available [4] [5], the AA tektite impact event occurred during a glacial cold period 803 ka Marine Isotope Stage 20a, hence Sunda Land presumably was dry. This well may turn out to be more compatible with tektite structure and unmelted ejecta than underwater source rock.

ODP leg 184 , borehole 1143 is located at $9^{\circ} 21^{\prime} 43.2^{\prime \prime} \mathrm{N}, 113^{\circ} 17^{\prime} 6.6^{\prime \prime} \mathrm{E}$, on the SW margin of the Archipelago, a site that just barely touches the outermost discernible rim of the crater [11] [12] $]^{4}$. One would not expect a drill hole at that ODP location 1143 to contain any impactites, especially considering this was an oceanic impact and the huge $275 \mathrm{~km}$ size is probably due in part to the water wave moving the seafloor along and making ground swells that way. The hole contains microtektites as well as unmolten ejecta from the Sunda shelf country rock.

Only one atoll was cored, the date was Pleistocene. This is the only solid age for the Dangerous Ground.

Also reported from this and other sites is a volcanic ashlayer that occurs just above the AA microtektites. While several investigators attribute this to supervolcano Toba on Sumatra, the date stated of $840 \mathrm{ka}$ for a mid-Pleistocene Toba eruption is significantly earlier than the $803 \mathrm{ka}$ data for the AA tektite impact, so we can exclude Toba and instead suggest the ash layer is a likely case of impact ${ }^{4}$ ODP website http://www-odp.tamu.edu/publications/184_IR/chap_01/chap_01.htm 
volcanism [10].

Likewise in the general area is ODP leg 184 borehole 1144 located at $20^{\circ} 3^{\prime} 10.8^{\prime \prime} \mathrm{N}, 117^{\circ} 25^{\prime} 8.4^{\prime \prime} \mathrm{E}$, a site that is $965 \mathrm{~km}$ almost due North of the Archipelago. Hole $1144 \mathrm{~A}$ is of some interest as having more abundant AA microtektites than any other site. This fact has misled Glass-Koeberl and others to seek the crater further North on the Asian continent [11] [12].

The Sunda shelf as source material for the AA tektites is well compatible with results of studies of their ${ }^{10} \mathrm{Be}$ content [16].

\section{Summary \& Conclusions}

The Spratlies Archipelago structure with its giant $275 \mathrm{~km}$ size, recent appearance, and its exploding in the middle of a collapsing continental slope of Sunda Land is the ideal source formation for the AA tektites.

A reverse butterfly ejecta pattern for the strewnfield with a predominantly southerly extent may be explained because in this direction the proportion of soil overburden converted into ejecta was largest, as the exploding cosmic body departed NE-ward from the Sunda shelf.

These events also serve to explain the fault system in the SW of the South China Sea. Much geological work will be needed for confirmation of my inferences by the exacting methods for which this science is known, by investigating in detail the features of this large area impact structure to which I have been able to draw attention in this first, tentative essay.

Clearly, a large amount of the weakly consolidated continental slope sediments was blown into space as AA tektites, therefore serves as a likely alternative for the Richard Muller interplanetary dust cloud and as the likely explanation for the mid-Pleistocene transition to a 100 ka glacial cycle of greater severity than the preceding $40 \mathrm{ka}$ Milankovitch cycle at about $800 \mathrm{ka}$.

There was a total regional SE Asian extinction event from the AA tektite impact that in particular wiped out the human population, early members of a race related to the Papua/ Melanesians, to people living in India and West to Aden, perhaps the Ainu, and probably ancestral hominin population of Flores Island known by its lithic technology of $1 \mathrm{Ma}$ age discovered by archaeologist Mike Morwood, Auckland NZ.

\section{References}

[1] Muller, R.A. and MacDonald, G.J. (1995) Glacial Cycles and Orbital Inclination. Nature, 377, 107-108. https://doi.org/10.1038/377107b0

[2] Muller, R.A. and MacDonald, G.J. (1997) Glacial Cycles and Astronomical Forcing. Science, 277, 215-218. https://doi.org/10.1126/science.277.5323.215

[3] Muller, R.A. (2002) Avalanches at the Core-Mantle Boundary. Geophysical Research Letters, 29, 41-1 to 41-4. https://doi.org/10.1029/2002GL015938

[4] Yamei, H., Potts, R., Baoyin, H., Zhengtang, G., Dieno, A., Wei, W., Clark, J., Guangmao, X. and Weiwen, H. (2000), Mid-Pleistocene Acheulean-Like Stone Technology of the Bose Basin, South China. Science, 287, 1622-1626. 
https://doi.org/10.1126/science.287.5458.1622

[5] Zhou, L.P. and Shackleton, N.J. (1999) Misleading Positions of Geomagnetic Reversal Boundaries in Eurasian Loess and Implications for Correlation between Continental and Marine Sedimentary Sequences. Earth and Planetary Science Letters, 168, 117-130. https://doi.org/10.1016/S0012-821X(99)00052-7

[6] Larson, G. and Schaetzl, R. (2001) Origin and Evolution of the Great Lakes. Journal of Great Lakes Research, 27, 518-546. https://doi.org/10.1016/S0380-1330(01)70665-X

[7] Pillans, B. (2003) Subdividing the Pleistocene Using the Matuyama-Brunhes Boundary (MBB): An Australasian Perspective. Quaternary Science Reviews, 22, 1569 1577. https://doi.org/10.1016/S0277-3791(03)00078-7

[8] Chalk, T.B., et al. (2017) Causes of Ice Age Intensification across the Mid-Pleistocene Transition. Proceedings of the National Academy of Science USA, 114, Early Edition. https://doi.org/10.1073/pnas.1702143114

[9] Burchard, H.G.W. (2017) Younger Dryas Comet 12,900 BP. Open Journal of Geology, 7, 193-199. https://doi.org/10.4236/ojg.2017.72013

[10] Burchard, H.G.W. (2016) Meteorite Impact Origin of the Yellowstone Hotspot. Open Journal of Philosophy, 6, 412-419. https://doi.org/10.4236/ojpp.2016.64038

[11] Lee, M.Y. and Wei, K.Y. (2000) Australasian Microtektites in the South China Sea and the West Philippine Sea: Implications for Age, Size, and Location of the Impact Crater. Meteoritics \& Planetary Science, 35, 1151-1155. https://doi.org/10.1111/j.1945-5100.2000.tb01504.x

[12] Glass, B.P. and Koeberl, C. (2006) Australasian Microtektites and Associated Impact Ejecta in the South China Sea and the Middle Pleistocene Supereruption of Toba. Meteoritics \& Planetary Science, 41, 305-326. https://doi.org/10.1111/j.1945-5100.2006.tb00211.x

[13] Liang, X., Wei, G., Shao, L., Li, X. and Wang, R. (2001) Records of Toba Eruptions in the South China Sea: Chemical Characteristics of the Glass Shards from 1143A. Science in China Series D: Earth Sciences, 44, 871-878. https://doi.org/10.1007/BF02907078

[14] Ding, W.W. and Li, J.B. (2016) Propagated Rifting in the Southwest Sub-Basin, South China Sea: Insights from Analogue Modelling. Journal of Geodynamics, 100, 71-86. https://doi.org/10.1016/j.jog.2016.02.004

[15] Hutchison, C.S. and Vijayan, V.R. (2010) What Are the Spratly Islands? Journal of Asian Earth Sciences, 39, 371-385. https://doi.org/10.1016/j.jseaes.2010.04.013

[16] Aggrey, K., Tonzola, C., Schnabel, C., de Nicola, P., Herzog, G.F., Wasson, J.T., Glass, B.P., Brown, L., Tera, F., Middleton, R. and Klein, J. (2004) Beryllium-10 in Australasian Tektites: Constraints on the Location of the Source Crater. Geochimica et Cosmochimica Acta, 68, 3883-3896. https://doi.org/10.1016/j.gca.2004.03.026 